\title{
Autoradiographic Localization and Characterization of Spinal Cord Substance P Binding Sites: High Densities in Sensory, Autonomic, Phrenic, and Onuf's Motor Nuclei ${ }^{1}$
}

\author{
CLIVEL G. CHARLTON AND CINDA J. HELKE ${ }^{2}$ \\ Department of Pharmacology, Uniformed Services University of the Health Sciences, Bethesda, Maryland 20811
}

\begin{abstract}
The presence of the neurotransmitter or neuromodulator, substance $P$ (SP), in the spinal cord implies that a discrete localization of SP receptors also occurs. To map the distribution of and to characterize SP binding sites in the spinal cord, light microscopic autoradiography was used. SP binding sites occurred in the dorsal horn, intermediolateral cell column (IML) and lamina $X$-region. In the ventral horn, the phrenic, Onuf's and sacral ventromedial motor nuclei were densely labeled. Other regions of the ventral horn were moderately labeled for SP binding sites. The localization of binding sites parallels the regional distribution of SP-containing nerve fibers in the spinal cord. A close correlation between the binding sites for SP and the presence of cholinesterase-stained neurons occurred, and suggest that the SP receptors are located on or proximal to cholinergic neurons. The density of the binding sites in the dorsal horn was highest in the sacral section, followed by the lumbar, thoracic and cervical section. In the lamina $X$ region, however, the density was highest in the thoracic followed by the sacral, lumbar and cervical sections. The high density binding of ${ }^{125} \mid$-BoltonHunter reagent labeled SP was inhibited, in a dose-dependent manner, by unlabeled SP. Quantification of the dosedependent inhibition binding, using computer densitometry, showed differences in the inhibition curves for the cervical lamina X-region and the IML as compared with the other loci containing high density binding sites. The differential sensitivity of the SP receptors to unlabeled SP suggests that there are heterogeneous receptors for SP in the spinal cord, which may be relevant to the role of SP in different spinal cord functions. The binding to specific motor nuclei in the ventral horn also suggest that SP may play a role in the function of specialized striated muscles.
\end{abstract}

Substance $P(S P)$ is widely distributed in the spinal cord. The highest levels are localized in the dorsal horn, ventral horn, intermediolateral cell column (IML), and lamina X-area (Hökfelt et al., 1975, 1976, 1977; Takahashi and Otsuka, 1975; Ditirro et al., 1981). In the dorsal horn, SP is mainly contained in terminals of small diameter

Received September 17, 1984;

Accepted November 9, 1984

\footnotetext{
${ }^{1}$ We wish to thank Mrs. Jean Bartlett for typing this manuscript, Mrs. Elaine Phillips for her technical assistance, and Ms. Jill Keeler for her suggestions. This work was supported by National Institutes of Health Grant NS-19317.

${ }^{2}$ To whom correspondence should be addressed.
}

dorsal root sensory neurons, whereas in the ventral horn and the $\mathrm{IML}$, the majority of SP fibers seem to be of superspinal origin (Hökfelt et al., 1977; Kanazawa et al., 1979; DeLanerolle and LaMotte, 1982; Helke et al., 1982).

$\mathrm{SP}$ has been implicated as a neurotransmitter in several spinal cord neuronal systems. The peptide is released from the spinal cord following potassium depolarization (Jessel and Iversen, 1977; Gamse et al., 1979), after electrical stimulation of the dorsal roots (Otsuka and Konishi, 1976), and following activation of nociceptive afferents (Yaksh et al., 1980). SP excites dorsal horn neurons that

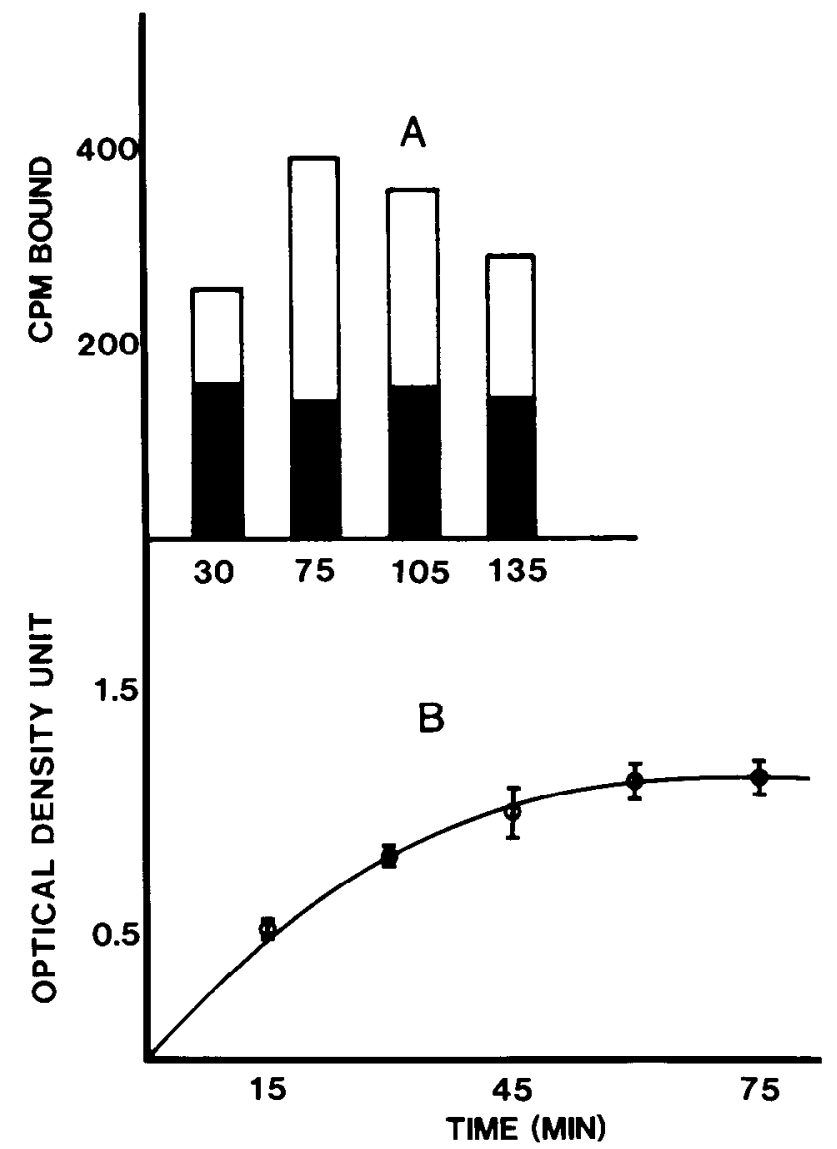

Figure 1. Time course of ${ }^{125} \mid \mathrm{BH}-\mathrm{SP}$ binding to rat spinal cord slices. At different incubation times, the washed and dried slices were scraped from the slides and wrapped in tissue paper, and the radioactivity was counted in a gamma counter $(A)$. The shaded section of each column represents nonspecific binding, the open section represents specific binding, and the total column represents total binding. In $B$, the mean optical density was determined for slices incubated for 15 to $75 \mathrm{~min}$. 


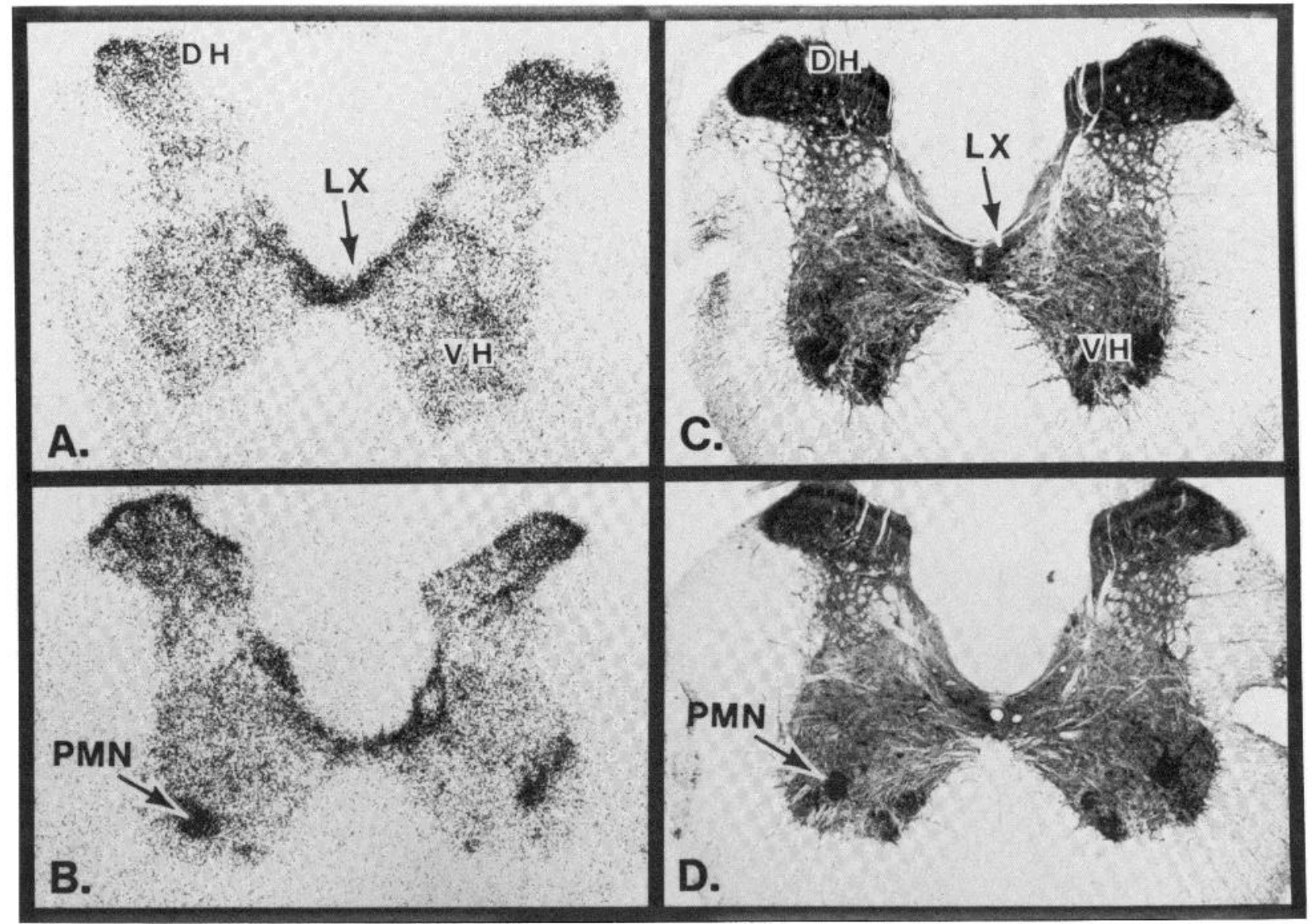

Figure 2. Brightfield photomicrographs of the autoradiograms of ${ }^{125} \mathrm{I}-\mathrm{BH}-\mathrm{SP}$ binding sites $(A$ and $B)$ and matched cholinesterase-stained slices $(C$ and $D)$ from the cervical section of the spinal cord. $A$ and $C$ were taken from the $C 2$ segment, and $B$ and $D$ were from $C 3-4$ segments. $D H$, dorsal horn; $L X$, lamina $\mathrm{X}$-region; $\mathrm{VH}$, ventral horn; $P M N$, phrenic motor nucleus.

are themselves excited by noxious stimuli (Henry, 1976; Piercey et al., 1980; Wright and Roberts, 1980). Studies with putative SP antagonists (Åkerman et al., 1982; Loewy and Sawyer, 1982; Keeler and Helke, 1984) showed that spinal cord SP affects not only transmission of noxious stimuli but also motor and autonomic functions, thus supporting observations that SP depolarized ventral horn motor neurons (Otsuka and Yanagisawa, 1980; Yanagisawa et al., 1982) and preganglionic sympathetic neurons (Backman and Henry, 1983). Therefore, as a neurotransmitter in the spinal cord, SP is probably involved in the regulation of nociception (Henry, 1976; Wright and Roberts, 1980), motor functions (Otsuka and Konishi, 1977; Yanagisawa et al., 1982), and autonomic functions (Åkerman et al., 1982; Keeler and Helke, 1984).

Although studies of SP receptors in homogenates of brain (Hanley et al., 1980; Perrone et al., 1983), salivary glands (Laing and Cascieri, 1980), and small intestine (Buck et al., 1984) and the autoradiographic localization in slices of forebrain (Shults et al., 1982; Quirion et al., 1983) and hindbrain (Helke et al., 1984) have been done, SP receptors in the spinal cord are not as well characterized. This is particularly surprising because the physiological roles of SP in the spinal cord have received much attention. Whereas binding of SP to synaptosomes prepared from whole spinal cord (Torrens et al., 1983) and to slices of thoracic spinal cord (Maurin et al., 1984) was reported, the segmental mapping and characterization of SP binding sites in the spinal cord were not studied. Recently, however, it was shown that there are qualitative and quantitative differences in SP binding sites in membrane homogenates of the rat spinal cord (Charlton and Helke, 1985). In this manuscript, the light microscopic autoradiographic localization, quantification, and characterization of SP receptors in segments of the rat spinal cord will be presented.

\section{Materials and Methods}

Animals and chemicals. Sprague-Dawley male rats (Taconic Farms, Germantown, NY) weighing 250 to $300 \mathrm{gm}$ were used in the study. The rats were housed in a colony room with a 12-hr light and 12-hr dark cycle and maintained at $23^{\circ} \mathrm{C}$. Food and water were supplied $a d$ libitum, and the animals were allowed to acclimatize for at least 1 week.

Synthetic SP was purchased from Peninsula Laboratories, San Carlos, CA. Trisma, bovine serum albumin (BSA), bacitracin, leupeptin, chymostatin, manganese chloride, and ethylenediamine-tetra-acetate (EDTA) were purchased from Sigma Chemical Company, St. Louis, MO. Radiolabeled monoiodinated Bolton-Hunter SP $\left.{ }^{125} \mathrm{l}-\mathrm{BH}-\mathrm{SP}\right)(2000 \mu \mathrm{Ci} / \mu \mathrm{M})$ was purchased from New England Nuclear, Boston, MA or was prepared in this laboratory, utilizing the method of Bolton and Hunter (1973). Purification of the latter was achieved by fractionating on Sephadex G-25 (fine) column using $0.025 \mathrm{M}$ $\mathrm{NaCl}: 0.01 \mathrm{~m}$ acetic acid containing $0.02 \%$ sodium azide and $0.2 \%$ BSA as the elution medium. The second peak eluted from the column contained ${ }^{125}$. $\mathrm{BH}-\mathrm{SP}$ and was further purified on SP-Sephadex $\mathrm{C}-25$ cation exchange resin. The SP-Sephadex C-25 packed column was washed with the above medium after the radioactive material was loaded, and ${ }^{125}$ - $\mathrm{BH}-\mathrm{SP}$ was eluted using $0.5 \mathrm{M} \mathrm{NaCl}$ in the medium instead of the $0.025 \mathrm{M}$ concentration.

Autoradiographic procedure. Rats were decapitated, and the spinal cord was removed by applying air pressure to one end of each section (cervical, thoracic, lumbar, or sacral) of the vertebral column removed from the rat. The spinal cord sections were rapidly frozen in powdered dry ice and immersed in cold saline contained in a small tube, and the entire contents were frozen and stored at $-78^{\circ} \mathrm{C}$ until they were sliced. Twenty- $\mu \mathrm{m}$ coronal and horizontal sections were cut in a cryostat $\left(-14^{\circ} \mathrm{C}\right)$ and mounted on chrome-alum-coated slides. The slide-mounted tissue slices were vacuum dried at $4^{\circ} \mathrm{C}$ overnight and stored at $-78^{\circ} \mathrm{C}$ until used.

The slices were preincubated at room temperature for $10 \mathrm{~min}$ in buffer consisting of $50 \mathrm{~mm}$ Tris- $\mathrm{HCl}, \mathrm{pH} 7.4$, containing BSA $(0.02 \%)$, bacitracin $(40 \mu \mathrm{g} / \mathrm{ml})$, leupeptin $(4 \mu \mathrm{g} / \mathrm{ml})$, chymostatin $(2 \mu \mathrm{g} / \mathrm{ml})$, and EDTA $(2.5 \mathrm{~mm})$ and for $5 \mathrm{~min}$ in the Tris- $\mathrm{HCl}$ buffer containing $3 \mathrm{~mm} \mathrm{MnCl}$ instead of EDTA. 


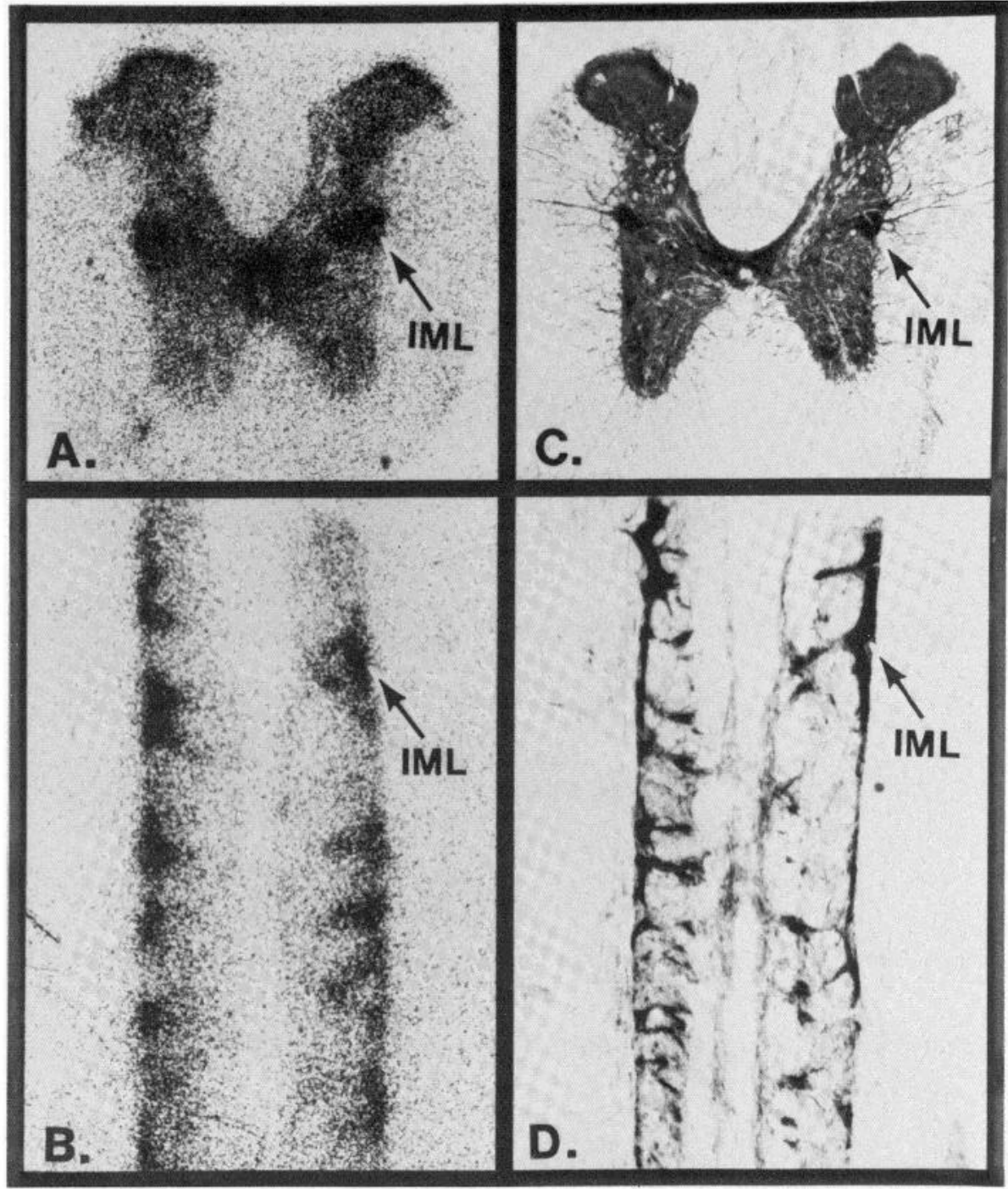

Figure 3. Brightfield photomicrographs of the autoradiograms of ${ }^{125}$ - $\mathrm{BH}-\mathrm{SP}$ binding sites $(A$ and $B$ ) and matched cholinesterase-stained slices (C and $D$ ) from the thoracic section of the spinal cord. $A$ and $C$ are horizontal, and $B$ and $D$ are longitudinal sections through the intermediolateral cell column (IML)

Incubation was performed for $75 \mathrm{~min}$ (except during the time-function studies) in the $\mathrm{Mn}^{++}$containing Tris- $\mathrm{HCl}$ buffer in the presence of $50 \mathrm{pM}^{125} \mathrm{I}-\mathrm{BH}-\mathrm{SP}$, with (nonspecific binding) or without (total binding) $1 \mu \mathrm{M}$ unlabeled SP. The slides were washed in cold buffer for 4 consecutive 30 -sec periods and dried by a stream of cool air. To test whether specific binding of ${ }^{125} 1-\mathrm{BH}-\mathrm{SP}$ occurred and to determine the time-course of binding, slices were scraped from slides and folded in tissue paper, and the radioactivity was counted in a gamma counter. The dried slides were juxtaposed with LKB Ultrofilm ${ }^{3} \mathrm{H}$ for 3 days, after which the films were processed in Kodak GBX developer for $4 \mathrm{~min}$, rinsed for $30 \mathrm{sec}$, fixed for $4 \mathrm{~min}$, thoroughly washed, and air dried.

The autoradiograms were analyzed using a computerized densitometry system as described previously (Goochee et al., 1980). Briefly, the autoradiograms were scanned by an optical densitometer, specific loci were outlined, and the mean optical density from various regions was determined. Similar tissue slices were processed for acetylcholinesterase-containing neurons by the thiocholine method (Koelle, 1955). Photomicrographs were prepared from matched autoradiograms and acetylcholinesterase-processed slices.

\section{Results}

${ }^{125} /-B H-S P$ binding as a function of time. Figure $1 A$ shows a histogram illustrating the binding of ${ }^{125}$ - $\mathrm{BH}$-SP to spinal cord adjacent slices as a function of incubation time. While the nonspecific binding (shaded columns) was constant, the specific binding (open columns) was highest at $75 \mathrm{~min}$, and it decreased for the 105- and 135-min incubation periods. At $30 \mathrm{~min}$ of incubation, the specific binding represents about $40 \%$ of the total binding; at $75 \mathrm{~min}$, it represents $64 \%$, while at 105 and 135 min, respectively, the values were 57 and $50 \%$. As shown in Figure 5 , the nonspecific binding is of low density and occurred over the entire surface of the white and grey matter of the spinal cord, with slightly higher density in the grey matter. The mean optical density of the autoradiogram of serial slices from the cervical spinal cord was also used to measure ${ }^{125} \mathrm{I}-\mathrm{BH}-\mathrm{SP}$ binding as a function of time (Fig. $1 B$ ). Total binding increased in time and reached a plateau within 60 to $75 \mathrm{~min}$. The measuring of binding using $(A)$ seems to be comparable with the optical density measures $(B)$ since, in both cases, the 30 -min binding represents about $70 \%$ of the binding at $75 \mathrm{~min}$.

Photomicrographic demonstration of binding sites. The binding of ${ }^{125} \mathrm{I}-\mathrm{BH}-\mathrm{SP}$ to slices from the cervical spinal cord is shown in Figure 2. In the upper cervical (approximately C2) spinal cord (Fig. $2 A)$, the highest density of binding sites occurred in the lamina 1 and in the lamina X-regions, extending to the posterior cornucommissuralis nucleus on the inner border of laminae $\mathrm{V}, \mathrm{VI}$, and $\mathrm{VII}$. Moderate density of binding occurred in lamina II. At the level of C3-4, distinct and high-density binding occurred in the phrenic motor nucleus (Fig. $2 B$ ), in addition to the binding in laminae $X$, and the dorsal horn. Figure 2, $C$ and $D$, shows corresponding sections stained to demonstrate acetylcholinesterase-containing neurons.

Brightfield photomicrographs of ${ }^{125} \mathrm{I}-\mathrm{BH}-\mathrm{SP}$ binding sites are shown in coronal (Fig. $3 A$ ) and horizontal sections (Fig. $3 B$ ) of the thoracic spinal cord, along with corresponding cholinesterase-stained sections (Fig. 3, $C$ and D). A high density of ${ }^{125}$ - $\mathrm{BH}-\mathrm{SP}$ binding sites 
Figure 4. Brightfield photomicrograph of the autoradiograms of ${ }^{125}$-BH-SP binding sites $(A$ to $C$ ) and matched cholinesterase-stained slices ( $D$ to $F$ ) from lumbar and sacral sections. $A$ and $D$ represent slices taken from L4-5, $B$ and $E$ represent those from $S 1$, and $C$ and $F$ represent those from S2-3. $O N$, Onuf's nucleus; $V M$, ventromedial nucleus; $S P N$, sacral parasympathetic nucleus. See Figure 2 for other abbreviations.
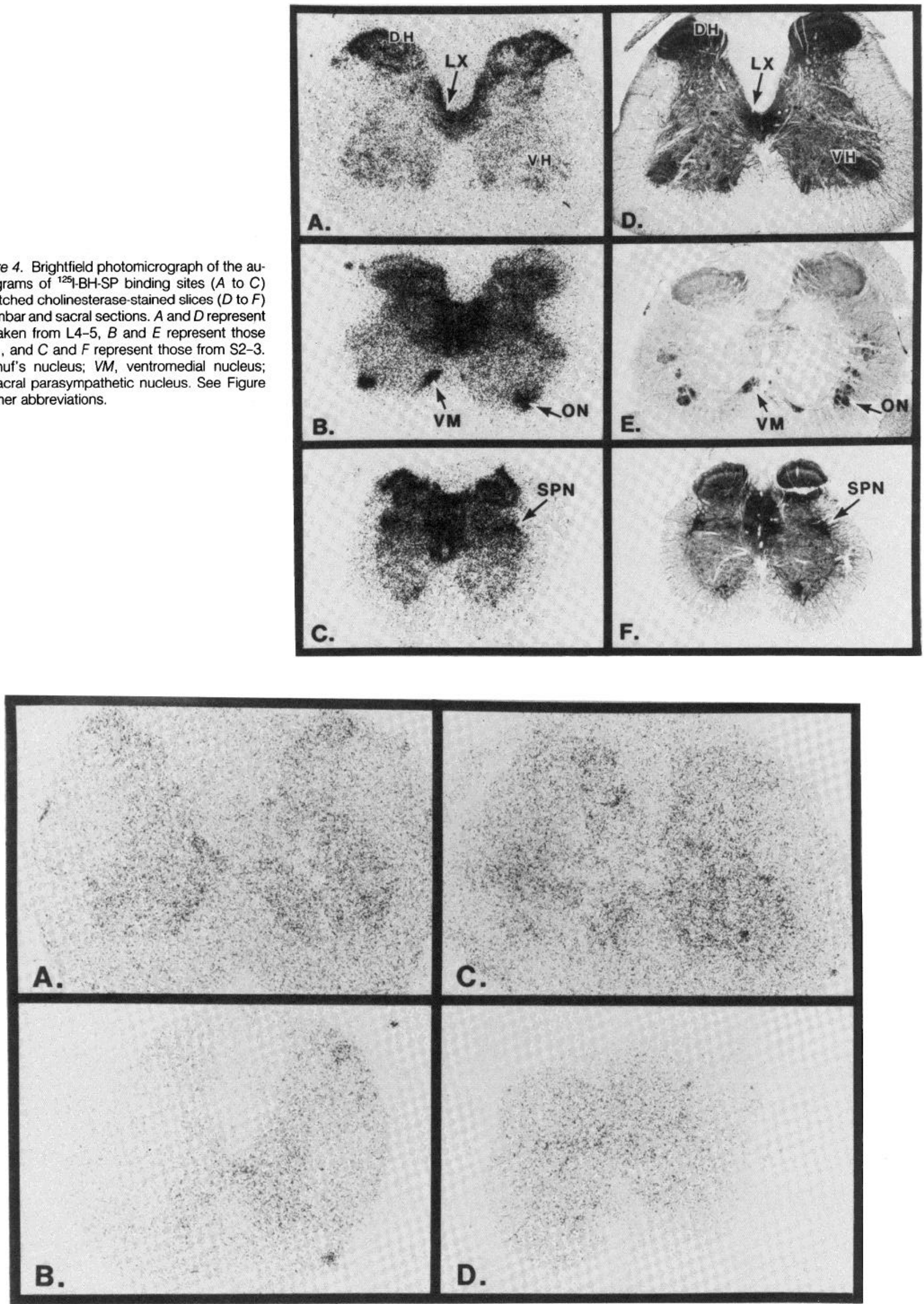

Figure 5. Brightfield photomicrographs of the autoradiograms of nonspecific ${ }^{125} \mathrm{-BH}-\mathrm{SP}$ binding sites in cervical $(A)$, thoracic $(B)$, lumbar $(C)$, and sacral (D) sections of the spinal cord. 
TABLE I

Substance $P$ receptor densities in loci of sections from the rat spinal cord

Optical densities were determined from autoradiograms of ${ }^{125}$ - $\mathrm{BH}-\mathrm{SP}$ binding to $20-\mu \mathrm{m}$ slices, taken $600 \mu \mathrm{m}$ apart along each section of the spinal cord. The values represent mean of optical density unit (maximum 2.000). $N=5$ for the cervical section and 8 for all other sections.

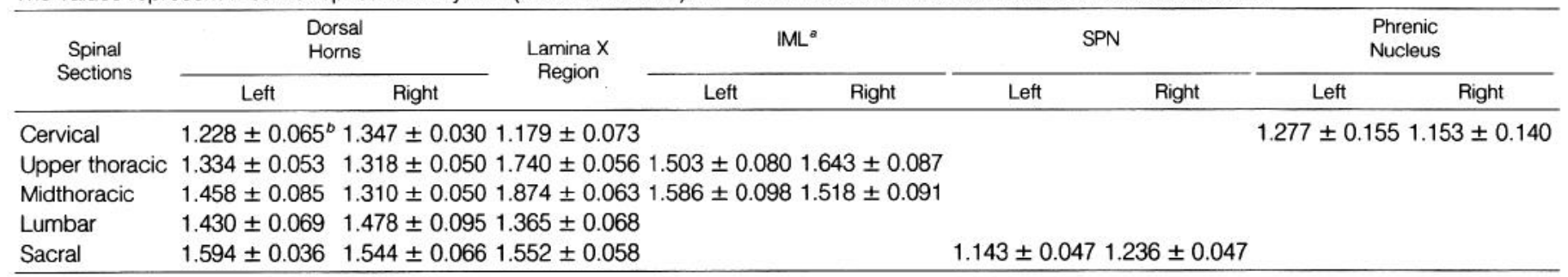

${ }^{a} \mathrm{IML}$, intermediolateral cell column; SPN, sacral parasympathetic nucleus.

${ }^{b}$ Mean \pm SE.

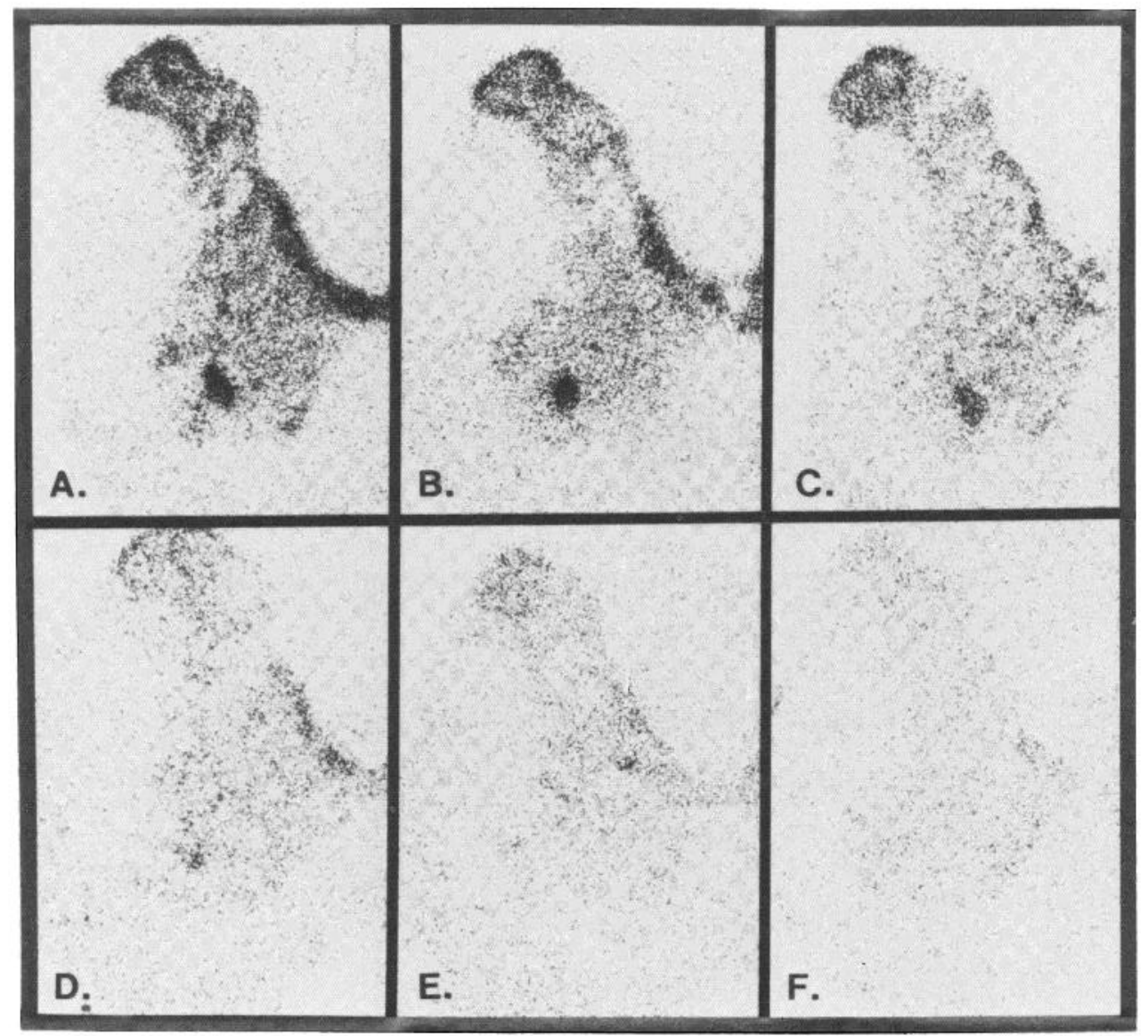

Figure 6. Brightfield photomicrographs of autoradiograms of the dose response inhibition of binding of ${ }^{125}$-BH-SP by unlabeled SP in cervical spinal cord slices. Concentrations of unlabeled SP used to displace ${ }^{125}$ - $\mathrm{BH}-\mathrm{SP}$ binding to slices are: $A, 0 \mathrm{nM} ; B$, $0.031 \mathrm{~nm} ; C, 0.125 \mathrm{~nm} ; D, 0.5 \mathrm{~nm} ; E, 2.0$ $\mathrm{nM}$; and $F, 200.0 \mathrm{nM}$.

occurred in the dorsal horn and lamina X. Very distinct high-density binding was also visualized in the IML. The binding in the IML is highlighted in the horizontal section $(B$, photomicrograph of autoradiogram and $D$, cholinesterase-staining) dissecting the IML. It should be noted that the high-density binding of ${ }^{125} \mathrm{I}-\mathrm{BH}-\mathrm{SP}$ in the IML is irregular in dimension and is noncontinuous, as shown in the horizontal section. This is due to the binding of SP to the noncontinuous cellular aggregations of the IML and the nucleus intercalatus, which extends between the IML and central canal. Although high-density cholinesterase-stained neurons occurred in the ventral horn of the thoracic spinal cord (Fig. $3 C$ ), a proportionately high density of SP binding did not occur in the ventral horn (Fig. $2 A$ ).

Figure 4 shows brightfield photomicrographs of autoradiograms of ${ }^{125} \mathrm{I}-\mathrm{BH}$-SP binding sites $(A)$ and the corresponding cholinesterasestained slice $(D)$ in the lumbar section. High-density binding sites occurred mainly in lamina I and II of the dorsal horn and in the lamina $\mathrm{X}$-region, including the inner border of laminae $\mathrm{V}, \mathrm{VI}$, and $\mathrm{VII}$.
Scattered lower-density binding sites also occurred in the ventral horn which correspond with the cholinesterase-stained neurons shown $(D)$.

In the sacral section, significant binding of ${ }^{125} \mathrm{I}-\mathrm{BH}-\mathrm{SP}$ occurred in the dorsal three-fifths of the grey matter. High-density binding sites were observed in the dorsal horn and lamina X-region in slices taken from the S1 and S2-3 segments. In the S1 slice (Fig. 4B), distinct high-density binding also occurred in loci homologous with the Onuf's and ventromedial motor nuclei, whereas, in the S2-3 slice (Fig. $4 C$ ), high-density binding occurred in the sacral parasympathetic nucleus. The binding sites correspond closely with highintensity cholinesterase-stained neurons. However, in the ventral horn, high intensity of cholinesterase staining also occurred (Fig. 4F, ventral tip) without correspondingly dense binding of ${ }^{125} \mathrm{HH}-\mathrm{SP}$.

Figure 5 shows brightfield photomicrograph of autoradiograms of nonspecific binding of ${ }^{125} \mathrm{I}-\mathrm{BH}-\mathrm{SP}$ in the cervical $(A)$, thoracic $(B)$, lumbar $(C)$, and sacral $(D)$ sections of the spinal cord. High-density 


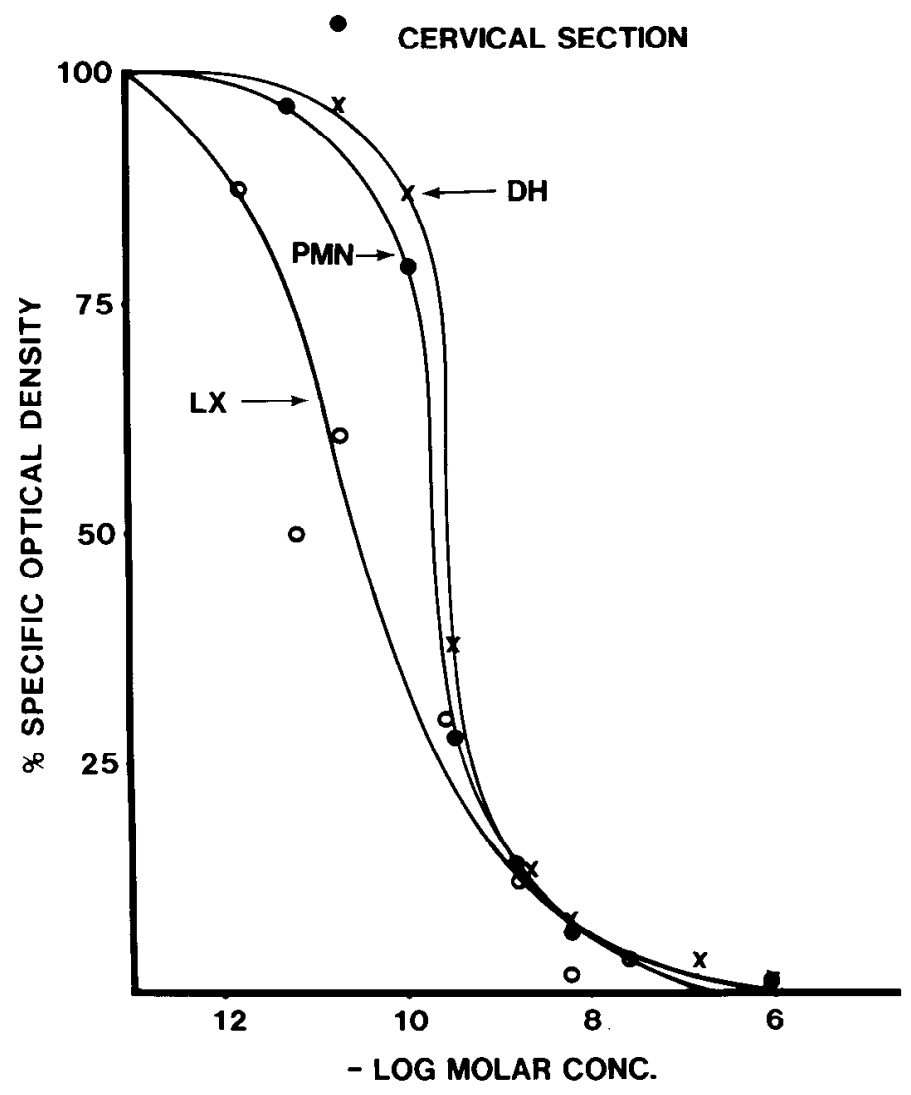

Figure 7. Inhibition curves for ${ }^{125} \mathrm{I}-\mathrm{BH}-\mathrm{SP}$ binding to loci of the cervical spinal cord. Slices were incubated with ${ }^{125} \mathrm{-BH}-\mathrm{SP}$ with graduated concentrations of unlabeled SP. The optical densities were determined for the highdensity binding sites from the autoradiograms and plotted against the SP concentrations used. $D H$, dorsal horn; $P M N$, phrenic motor nucleus; $L X$, lamina $\mathrm{X}$-region.

binding to all loci in the respective sections was inhibited. Nonspecific binding is slightly higher in the grey matter than in the white matter.

Densitometric quantification of binding sites. A comparison of the density of ${ }^{125}$ - $\mathrm{BH}-\mathrm{SP}$ binding sites in loci of the spinal cord and an estimation of the variation in the density of the binding sites along the spinal cord were done. Slices from the cervical, thoracic, lumbar, and sacral sections were taken at an interval of $600 \mu \mathrm{M}$. Densitometric determination of ${ }^{125} \mathrm{~F}-\mathrm{BH}-\mathrm{SP}$ binding sites from autoradiograms are shown (Table I) for the dorsal horn, lamina $X$-region, IML, sacral parasympathetic nucleus (SPN), and phrenic nucleus. No significant differences in the density of binding sites for the right and left dorsal horn, IML, SPN, and phrenic nucleus occurred. However, in the dorsal horn, receptor density showed progressive increment from the cervical (1.22 and 1.34 optical density units) through the thoracic and lumbar sections to the sacral, where the mean value was 1.56 units. For the lamina X-region, the density of binding sites was highest in the thoracic section (upper, 1.74; middle, 1.87 unit), followed by the sacral (1.55 unit), lumbar ( 1.31 unit), and cervical (1.17 unit) sections. Of the sections studied, only the thoracic and sacral sections showed binding in the lateral horn (IML and SPN). In the ventral horn, high-density binding occurred in the phrenic motor nucleus of the cervical section and the Onuf's and ventromedial nuclei of the sacral section. Although the slices represent crosssections taken at intervals within $2400 \mu \mathrm{M}$ for the cervical and 4200 $\mu \mathrm{M}$ for the other sections, it is clear (from the value of the standard errors) that the binding of ${ }^{125} \mathrm{I}-\mathrm{BH}-\mathrm{SP}$ showed consistent density in the respective sections.

Inhibition of ${ }^{125} / \mathrm{BH}-\mathrm{SP}$ binding, determined densitometrically. The inhibition of the binding of ${ }^{125}$ - $\mathrm{BH}-\mathrm{SP}$ from adjacent slices
THORACIC SECTION

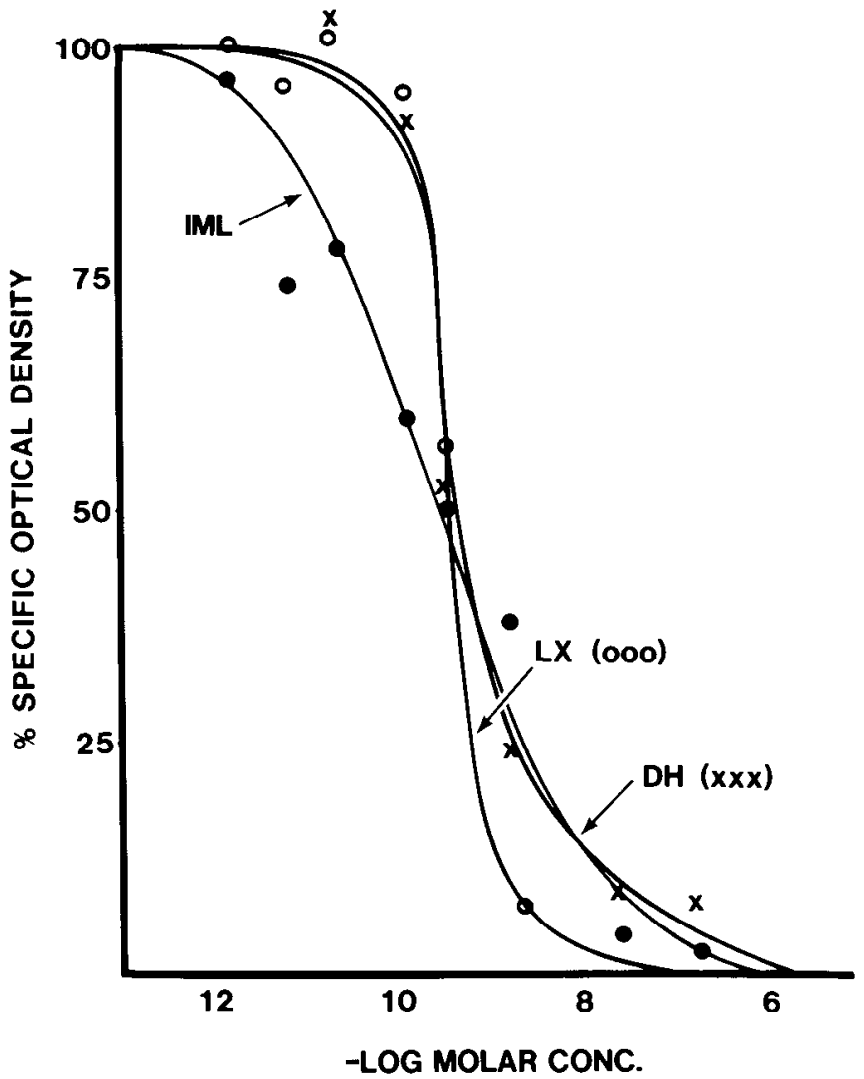

Figure 8. Inhibition curves for ${ }^{125} \mathrm{I}-\mathrm{BH}-\mathrm{SP}$ binding to loci of the thoracic spinal cord. Slices were incubated with ${ }^{125} \mathrm{I}-\mathrm{BH}-\mathrm{SP}$ with graduated concentrations of unlabeled SP. $I M L$, intermediolateral cell column; $L X$, lamina $X$-region; $\mathrm{DH}$, dorsal horn.

prepared from sections of the spinal cord was examined. Photomicrographs of typical autoradiograms show a dose response inhibition of ${ }^{125}$-BH-SP by unlabeled SP (Fig. 6). Photomicrograph $A$ represents total binding, and $B$ to $F$ represents binding in the presence of $0.031,0.125,0.5,2.0$, and $200.0 \mathrm{nM}$ of unlabeled SP. The mean specific optical density of the loci with high ${ }^{125}$ - BH-SP binding sites were determined for the cervical, thoracic, lumbar, and sacral sections. Figure 7 shows the curves for the inhibition of ${ }^{125} \mathrm{I}-\mathrm{BH}-\mathrm{SP}$ binding to slices from the cervical spinal cord by unlabeled SP. The inhibition curves for the phrenic nucieus and the dorsal horn are similar and have $\mathrm{IC}_{50}$ of about 0.2 and $0.4 \mathrm{~nm}$, respectively. However, the inhibition of ${ }^{125}$ - $\mathrm{BH}$-SP binding to the lamina X-region were more sensitive to unlabeled $S P$ and had an $I C_{50}$ of $0.03 \mathrm{nM}$. $I \mathrm{C}_{50} \mathrm{~S}$ for the $\mathrm{IML}$, dorsal horn, and lamina $\mathrm{X}$-region in the thoracic section were similar $\left(\mathrm{IC}_{50}\right.$ of $\left.0.45 \mathrm{~nm}\right)$. However, at low doses of unlabeled SP, the IML seem to be more sensitive to the inhibition of ${ }^{125} \mathrm{I}-\mathrm{BH}-\mathrm{SP}$ binding. The $\mathrm{IC}_{25}$ was $\sim 0.05 \mathrm{nM}$ for the $\mathrm{IML}$ as compared to $0.30 \mathrm{nM}$ for the dorsal horn and lamina X-region (Fig. 8). In the lumbar section (Fig. 9), the inhibition curves were identical for the dorsal horn and lamina $X$-region $\left(\mathrm{IC}_{50}\right.$ approximately $\left.0.25 \mathrm{~nm}\right)$. Similarly, the curves for the $\mathrm{SPN}$, dorsal horn, and lamina X-region (Fig. 10) were alike $\left(\mathrm{IC}_{50}\right.$ approximately $0.5 \mathrm{nM}$ ) in the sacral, section.

\section{Discussion}

These experiments show the localization of high-density ${ }^{125} \mathrm{I}-\mathrm{BH}-$ SP binding sites in discrete loci of the rat spinal cord. Because the high-density binding was inhibited by $<1 \mu \mathrm{M}$ of unlabeled SP and because SP and BH-SP showed similar biological reactivity (Liang and Cascieri, 1980; Beaujouan et al., 1982), it appears that the binding sites represent biological receptors for SP. Furthermore, the 


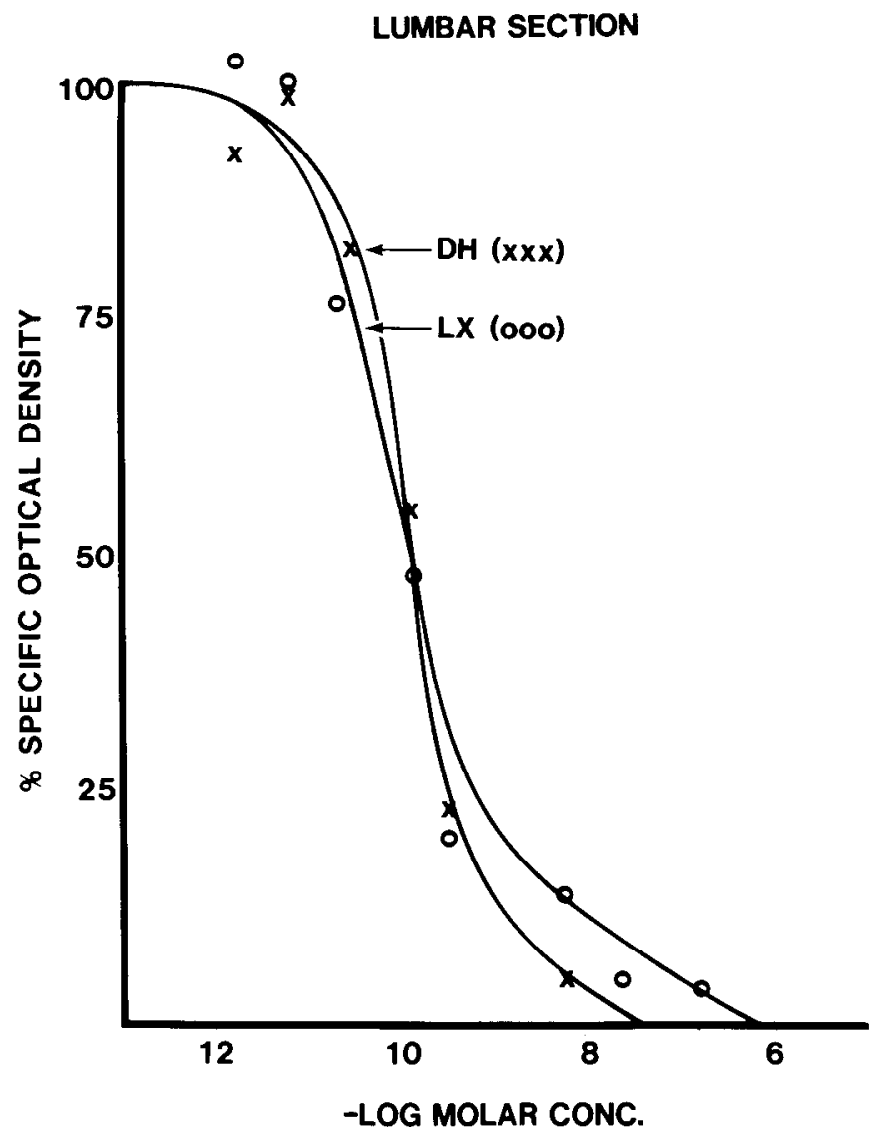

Figure 9. Inhibition curves for ${ }^{125}$-BH-SP binding to loci of the lumbar spinal cord. Slices were incubated with ${ }^{125} \mathrm{I}-\mathrm{BH}-\mathrm{SP}$ with graduated concentrations of unlabeled SP. $D H$, dorsal horn; $L X$, lamina X-region.

distribution of SP receptors is consistent with the localization of SPcontaining nerve fibers in the spinal cord.

The time course of binding to slices resembles the binding to membrane homogenates (Charlton and Helke, 1985). Equilibrium was reached in $75 \mathrm{~min}$ (Fig. 1B). At 105 and $135 \mathrm{~min}$, however, decreases of specific binding were evident (Fig. 1A). This gradual decrease may represent changes in receptor state rather than metabolism of ${ }^{125} \mathrm{I}-\mathrm{BH}-\mathrm{SP}$, because the peptidase inhibitors leupeptin, chymostatin, and bacilracin (Lee et al., 1983) were added to the medium. The nonspecific binding was higher for the slice study $(36 \%)$ than for the membrane homogenate study (approximately $12.5 \%$ ). This may be so because nonspecific binding is probably associated mainly with soluble cellular material, the majority of which was removed during membrane preparation. Nonspecific binding to the slices, though, was of low density and was distributed over the surface of the tissue slices (Fig. 5)

The occurrence of SP binding sites in the dorsal horn, IML, lamina $X$-region, and phrenic motor nucleus and, to a lesser extent, in other regions of the ventral horn parallel the regional distribution of SP. containing nerve fibers in the spinal cord (Takahashi and Otsuka, 1975; Hökfelt et al., 1976; Ljungdahl et al., 1978; Ditirro et al., 1981; Holtman et al., 1984) and is relevant to the rationale of SP as a neurotransmitter or neuromodulator in the spinal cord. SP receptors in the dorsal horn are, in all likelihood, a component of the SP system that has been associated with nociception (Henry, 1976; Hökfelt et al., 1977) and probably reflex motor control (Piercey et al., 1981. Yanagisawa et al., 1982). The ventral horn SP binding sites are comparatively low in density and/or extent and correlate with sparce SP-containing neuronal system in the ventral horn (Takahashi and Otsuka, 1975) that may also function in motor control (Ryall and Belcher, 1977; Otsuka and Yanagisawa, 1980). The binding in the $\mathrm{ML}$ is probably associated with a SP-nerve terminal system that
0 $x$ SACRAL SECTION

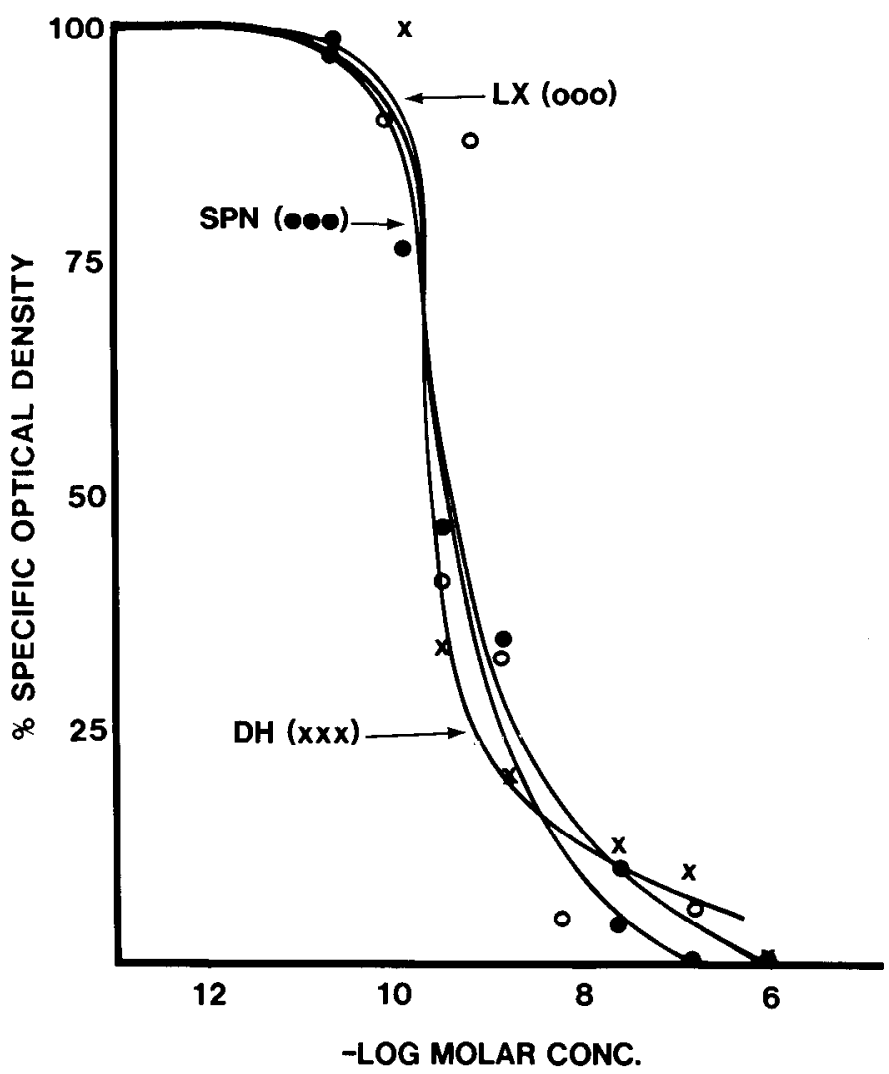

Figure 10. Inhibition curves for ${ }^{125}$ - $\mathrm{BH}-\mathrm{SP}$ binding to loci of the sacral spinal cord. Slices were incubated with ${ }^{125}-\mathrm{BH}-\mathrm{SP}$ with graduated concentrations of unlabeled SP. SPN, sacral parasympathetic nucleus; $L X$, lamina $X$ region; $D H$, dorsal horn.

originates in the ventral medulla (Helke et al., 1982) and has been implicated in the regulation of information to the spinal sympathetic preganglionic neuronal cell bodies in the IML (Loewy and Sawyer, 1982; Backman and Henry, 1983; Keeler and Helke, 1984). That the IML SP system regulates autonomic function may also be true for a sacral SP system, since high-density SP binding occurred in the sacral parasympathetic nucleus.

SP binding sites in the phrenic motor nucleus were very distinct (Fig. 2B) and complement the recently identified SP containing fibers in the phrenic nucleus (Holtman et al., 1984). The superspinal sources for the SP fibers are probably the nucleus raphe pallidus and obscurus (Holtman et al., 1984). It should be recalled that neurons in the phrenic innervate the diaphragm; therefore the interaction of SP with receptors in the phrenic motor nucleus may serve to transduce superspinal information for respiratory control. It is of interest also that SP-like immunoreactivity has been observed and is transported in the phrenic nerve (Malthe-Sørenssen and Oktedalen, 1982). This suggests that a SP-SP coupled neuronal system may be involved in respiratory control via the diaphragm. That SP may be involved in the control of other specialized muscular system is a possibility, since high-density SP binding sites were associated with nuclei homologous with the levator ani motorneurons, i.e., the ventromedial nucleus, as well as the Onuf's nucleus, which innervates the external sphincters of the anus and bladder (Mannen et al., 1977; Sato et al., 1978). High-density SP binding sites were also found in the lamina $X$-region in all sections of the spinal cord. The occurrence of SP receptors in the lamina $X$-region is complementary with the SP-like varicosities in the opposum (Ditirro et al., 1981) and rats (Gibson et al., 1981; Barber et al., 1979). The function 
of this SP system is not known, but the varicosities stream horizontally and seem to be derived from spinal interneurons, therefore may serve in transneuronal communication.

The binding of ${ }^{125} \mathrm{I}-\mathrm{BH}-\mathrm{SP}$ to spinal cord sections correlate closely with the occurrence of cholinesterase-stained neurons, except in some regions of the ventral horn, where the density of ${ }^{125} \mathrm{I}-\mathrm{BH}-\mathrm{SP}$ binding sites was generally low as compared with the cholinesterasestaining. This suggests that SP receptors are located on or are proximal to cholinergic neurons but that all cholinergic neurons do not share that association with the location of SP receptors.

The densitometric quantification of the dose-response inhibition of binding of ${ }^{125} \mathrm{I}-\mathrm{BH}-\mathrm{SP}$ showed that the SP receptors in loci of the spinal cord are variably sensitive to the unlabeled SP. The inhibition curve for the lamina $X$-region, including the inner border of laminae $V, V I$, and $V I I$, of the cervical spinal section, showed an $I_{50}$ that is ten times less than the $\mathrm{IC}_{50}$ for the other loci studied. It is of interest to note that the $\mathrm{IC}_{50} \mathrm{~S}(0.2$ to $0.5 \mathrm{nM})$ for all regions except the lamina $X$-region in this study are statistically identical to that (average, 0.46 nM) derived from membrane homogenate study (Charlton and Helke, 1985). The differences in sensitivity to cold SP indicate differences in receptors and correlate with the previous observation that showed the inhibition of ${ }^{125} \mathrm{I}-\mathrm{BH}-\mathrm{SP}$ from membranes prepared from the cervical spinal cord to be more sensitive to cold SP (Charlton and Helke, 1985). The slope of the curve for the IML was much less than the slope of the curves for the dorsal horn and lamina X-region of the thoracic spinal cord. At low doses of unlabeled SP, the receptors in the IML were more sensitive to the inhibitory effects, whereas at high doses, the $I M L$ receptors were equally or less sensitive to the inhibitory effect of unlabeled SP. Whether this gradual inhibitory effect is relevant to the functioning of the IML SP system in autonomic regulation remains to be known.

Finally, this study shows the discrete localization of SP receptors in sections of the spinal cord. The distribution of the receptors correlates with the localization of SP-containing nerve terminals and shows a similarity to the distribution of cholinesterase-stained neurons in the spinal cord, except in the ventral horn, where high-density SP binding sites seem to occur only in nuclei that innervate specialized striated muscles. As mentioned before (Piercey et al., 1981; Stewart et al., 1982; Lee et al., 1983; Charlton and Helke, 1985) and as reported here, heterogeneous SP receptors seem to occur in the central nervous system. The discrete localization of SP receptors in the spinal cord adds an element to the concept of a functional SP neuronal system in the spinal cord.

\section{References}

Åkerman, B., Rosell, S., and Folkers, K. (1982) Intrathecal (D-Pro ${ }^{2}$, D-Trp ${ }^{7.9}$ ). SP elicits hypoalgesia and motor blockade in the rat and antagonizes noxious responses induced by substance P. Acta Physiol. Scand. 114: 631-633.

Backman, S. B., and Henry, J. L. (1983) Effects of substance $P$ and thyrotropin-releasing hormone on sympathetic preganglionic neurons in the upper thoracic intermediolateral nucleus of the cat. Can. J. Physiol. Pharmacol. 62: 248-251.

Barber, R. P., Vaughn, J. E., Slemmon, R. J., Salvaterra, P. M., Roberts, E., and Leeman, S. E. (1979) The origin, distribution, and synaptic relationships of substance $P$ axons in rat spinal cord. J. Comp. Neurol. 194: 331-352.

Beaujouan, J. C., Torrens, Y., Herbet A., Dagnet, MC., Glowinski, J., and Porchiantz, A. (1982) Specific binding of an immunoreactive and biologically active ${ }^{125}$-labeled substance $P$ derivative to mouse mesencephalic cells in primary culture. Mol. Pharmacol. 22: 48-55.

Bolton, A. E., and Hunter, W. M. (1973) The labeling of proteins to high specific radioactivities by conjugation to a ${ }^{125}$-containing acylating agent. Biochem. J. 133: 529-539.

Buck, S. H., Maurin, Y., Burks, T. F., and Yamamura, H. I. (1984) High affinity ${ }^{3} \mathrm{H}$-substance $\mathrm{P}$ binding to longitudinal muscle membranes of the guinea pig small intestine. Life Sci. 34: 497-507.

Charlton, C. G., and Helke, C. J. (1985) Characterization and segmental distribution of ${ }^{125}$-Bolton-Hunter-labeled substance $\mathrm{P}$ binding sites in rat spinal cord. J. Neurosci. 5: 1292-1298.

DeLanerolle, N. C., and LaMotte, C. C. (1982) The human spinal cord:
Substance $\mathrm{P}$ and methionine-enkephalin immunoreactivity. J. Neurosci. 2: 1369-1386.

Ditirro, F. J., Ho, R. H., and Martin, G. F. (1981) Immunohistochemical localization of substance $P$, somatostatin and methionine-enkephalin in the spinal cord and dorsal root ganglia of the North American opossum, Didelphis Virginiana. J. Comp. Neurol. 198: 351-363.

Gamse, R., Molmar, A. and Lembeck, F. (1979) Substance P release from spinal cord sliccs by capsaicin. Life Sci. 25: 629-636

Gibson, S. J., Polak, J. M., Bloom, S. R., and Wall, P. D. (1981) The distribution of nine peptides in rat spinal cord with special emphasis on the substantia gelatinosa and on the area around the central canal (lamina X). J. Comp. Neurol. 201: 65-74.

Goochee, C., Rasband, W., and Sokoloff, L. (1980) Computerized densitometry and color coding of ${ }^{14} \mathrm{C}$-deoxyglucose autoradiography. Ann. Neurol. 7: $359-370$.

Hanley, M. R., Sandberg. B. E. B., Lee, C. M., Iversen, L. L., Brundish. D. E., and Wade, R. (1980) Specific binding of ${ }^{3} \mathrm{H}$-substance $P$ to rat brain membranes. Nature 286: 810-812.

Helke, C. J. (1982) Neuroanatomical localization of substance P: Implications for central cardiovascular control. Peptides (Fayetteville) 3: 479-483.

Helke, C. J., J. J. Neil, J. V. Massari, and A. D. Loewy (1982) Substance P neurons project from the ventral medulla to the intermediolateral cell column and ventral horn in the rat. Brain Res. 243: 147-152.

Helke, C. J., Shultz, C. W., Chase, T. N., and O'Donohue, T. L. (1984) Autoradiographic localization of substance $P$ receptors in rat medulla: Effect of vagotomy and nodose ganglionectomy. Neuroscience 12: 215223.

Henry, J. L. (1976) Effects of Substance P on functionally identified units in cat spinal cord. Brain Res. 114: 439-451.

Hökfelt, T. Kellerth, J., Nilsson, G. and Pernow, B. (1975) Experimental immunohistochemical studies on the localization and distribution of substance $P$ in cat primary sensory neurons. Brain Res. 100: 235-252.

Hökfelt, T., Elde, R., Johansson, O., Luft, R., Nilsson, G., and Arimura, A. (1976) Immunohistochemical evidence for separate populations of so. matostatin containing and substance $P$ containing primary afferent neurons in rat. Neurosci. Lett. 1: 131-136.

Hökfelt, T., Ljungdahl, A., Terenius, T., Elde, R., and Nilsson, G. (1977) Immunohistochemical analysis of peptide pathways possibly related to pain and analgesia: Enkephalin and substance P. Proc. Natl. Acad. Sci. U. S. A. 74: $3081-3085$

Holtman, J. R., Jr., Norman, W. P., and Gillis, R. A. (1984a) Projections from the raphe nuclei to the phrenic motor nucleus in the cat. Neurosci. Lett. 44: 105-111.

Holtman, J. R., Jr., Norman, W. P., Skirboll, L., Dretchen, K. L., Cuello, C., Visser, T. J., Hökfelt, T., and Gillis, R. A. (1984b) Evidence for 5-hydroxytryptamine, substance $P$, and thyrotropin-releasing hormone in neurons innervating the phrenic motor nucleus. J. Neurosci. 4. 1064-1071.

Jessel, T. M., and Iversen, L. L. (1977) Opiate analgesics inhibit substance $P$ release from rat trigeminal nucleus. Nature 268: $549-551$

Kanazawa, I., Sutoo, D., Ushima, I., and Saito, S. (1979) Effect of transection on choline acetyltransferase, thyrotropin releasing hormone, and substance $P$ in the cat cervical spinal cord. Neurosci. Lett. 13: 325-330.

Keeler, J. R., and C. J. Helke (1984) Pharmacologic evidence that substance $P$ is involved in bulbospinal cardiovascular control in the rat. Soc. Neurosci. Abstr. 12: 712

Koelle, G. B., (1955) The histochemical identification of acetylcholinesterase in cholinergic, adrenergic and sensory neurons. J. Pharmacol. Exp. Ther. 114: $167-184$

Lee, C. M., Javitch, J. A., and Snyder, S. H. (1983) ${ }^{3} \mathrm{H}$-Substance P binding to salivary gland membranes. Regulation by guanyl nucleotides and divalent cations. Mol. Pharmacol. 23: 563-569.

Liang, T., and Cascieri, M. A. (1980) Specific binding of an immunoreactive and biologically active ${ }^{125}$-labelled $N(1)$ acylated substance $P$ derivative to parotid cells. Biochem. Biophys. Res. Commun. 96: 1793-1799.

Ljungdahl, ̊., Hökfelt, T., and Nilsson, G. (1978) Distribution of substance P-like immunoreactivity in the central nervous system of the rat. I. Cell bodies and nerve terminals. Neuroscience 3: 861-943.

Loewy, A. D., and Sawyer, W. B. (1982) Substance P antagonist inhibits vasomotor responses elicited from ventral medulla in rat. Brain Res. 245 : 379-383.

Malthe-Sørensesen, D., and Oktedalen, O. (1982) Substance P-like immunoreactivity in the phrenic nerve and diaphragm: Axonal transport of substance $P$ in the phrenic nerve. Neurosci. Lett. 28: 269-274.

Mannen, T., Iwata, M., Toyokura, Y., and Nagashima, K. (1977) Preservation of a certain motoneurone group of the sacral cord in amyotropic latera 
sclerosis: Its clinical significance. J. Neurol. Neurosurg. Psychiatry 40: 464-469.

Maurin, Y., Buck, S. H., Wamsley, J. K., Burks, T. F., and Yamamura, H. I. (1984) Light microscopic autoradiographic localization of $\left[{ }^{3} \mathrm{H}\right]$ substance $P$ binding sites in rat thoracic spinal cord. Life Sci. 34: 1713-1716.

Otsuka, M., and Konishi, S. (1976) Release of substance P-like immunoreactivity from isolated spinal cord of newborn rat. Nature 264: 83-84.

Olsuka, M., and Kurishi, S. (1977) Electrophysiological and reurochernical evidence for substance $P$ as a transmitter of primary sensory neurons. In: Substance P, U. S. von Euler and B. Pernov, eds., pp. 207-214, Raven Press, New York.

Otsuka, M., and Yanagisawa, M. (1980) The effects of substance $P$ and baclofen on motor neurones of isolated spinal cord of the newborn rat. J. Exp. Biol. 89: 201-214.

Perrone, M. H., Diehl, R. E., and Haubrich, D. R. (1983) Binding of $\left[{ }^{3} \mathrm{H}\right]$ substance $P$ to putative substance $P$ receptors in rat brain memoranes. Eur. J. Pharmacol. 95: 131-133.

Piercey, M. F., Einspahr, F. J., Dobry, P. T. K., Schroeder, L. A., and Hollister, R. P. (1980) Morphine does not antagonize the substance $P$ mediated excitation of dorsal horn neurons. Brain Res. 186: 421-434.

Piercey, M. F., Schroeder, L. A., Folkers, K., Xu, J. C., and Horig, J. (1981) Sensory and motor functions of spinal cord substance P. Science 214: $1361-1363$.

Quirion, R., Shults, C. W., Moody, T. W., Pert, C. B., Chase, T. N., and O'Donohue, T. L. (1983) Autoradiographic distribution of substance $P$ receptors in rat central nervous system. Nature 303: 714-716.

Ryall, R. W., and Belcher, G. (1977) Substance P selectively blocks nicotine receptors on Ranshaw cells: A possible synaptic inhibitory mechanism Brain Res. 137: 376-380.

Sato, M., Mizuno, N., and Konishi, A. (1978) Localization of motor neurons innervating peroneal muscles: A HRP study in cat. Brain Res. 140: 149154.

Shults, C. W., Quirion, R., Jensen, R. T., Moody, T. W., O'Donohue, T. L. and Chase, T. N. (1982) Autoradiographic localization of substance $P$ receptors using ${ }^{125}$-substance $P$. Peptides (Fayetteville) 3: 1073-1075.

Stewart, J. M., M. E. Hall, J. Harkins, R. C. A. Frederickson, L. Terenius, T Hökfelt, and W. A. Krivoy (1982) A fragment of substance $P$ with specific central activity: SP-(1-7). Peptides 3: 831-857.

Takahashi, T., and Otsuka, M. (1975) Regional distribution of substance $P$ in the spinal cord and nerve roots of the cat and the effect of dorsal root section. Brain Res. 87: 1-11.

Torrens, Y., Beaujouan, J. C., Viger, A., and Glowinski, J. (1983) Properties of a ${ }^{125}$-substance $P$ derivative binding to synaptosomes from various brain structures and the spinal cord of the rat. Naunyn-Schmiedeberg's Arch. Pharmacol. 324: 134-139.

Wright, D. M., and Roberts, M. H. T. (1980) Responses of spinal neurons to a substance $P$ analogue, noxious pinch, and bradykinin. Eur. J. Pharmacol. 64: $165-167$.

Yaksh, T. L., Jessel, T. M., Gerrse R., Midge, A. W., and Leeman, S. E. (1980) Intrathecal morphine inhibits substance $P$ release from spinal cord in vivo. Nature 286: 155-157.

Yanagisawa, M., Otsuka, M., Konishi, S., Akagi, H., Folkers, K., and Rosell, S. (1982) A substance $P$ antagonist inhibits a slow reflex response in the spinal cord of the newborn rat. Acta Physiol. Scand. 116: 109-112. 